Orbis Tertius, vol. XXIII, $\mathrm{n}^{\circ}$ 28, e090, diciembre 2018. ISSN 1851-7811

Universidad Nacional de La Plata

Facultad de Humanidades y Ciencias de laEducación

Centro de Estudios de Teoría y Crítica Literaria

\title{
Primacía de lo espiritual. Arte e imágenes en la primera etapa de Criterio
}

\section{Laura Cabezas*}

* Universidad de Buenos Aires, Argentina

Cita sugerida: Cabezas, L. (2018). Primacía de lo espiritual. Arte e imágenes en la primera etapa de

Criterio. Orbis Tertius, 23(28), e090. https://doi.org/10.24215/18517811e090 BY NG SA http://creativecommons.org/licenses/by-nc-sa/4.0/deed.es AR 


\title{
Primacía de lo espiritual. Arte e imágenes en la primera etapa de Criterio
}

\author{
por Laura Cabezas \\ (Universidad Buenos Aires)
}

\begin{abstract}
RESUMEN:
La primera etapa (1928-1929) de la revista católica Criterio, presenta la convivencia - no exenta de conflicto-entre un pensamiento católico conservador y más tradicional y otro de tinte renovador, vinculado a escritores y artistas modernos. En relación con las reflexiones sobre arte contemporáneo y las imágenes que se ponen en circulación en sus páginas, se presenta una mirada modernizadora que se debate entre dos grandes corrientes: por un lado, la opción más esteticista vinculada con la vanguardia martinfierrista; por el otro, la preocupación por un arte popular y social. Entre ambas, se definen los limites y las posibilidades de una modernidad espiritual bajo el régimen católico.
\end{abstract}

Palabras Clave: Criterio - catolicismo-arte argentino - revistas culturales.

\section{Abstract:}

The first period of the Catholic magazine Criterio, between 1928 and 1929, presents a coexistence not devoid of conflict between a more traditional and conservative Catholic thought and a renovation in ideas linked to modern writers and artists. In relation to the reflections on contemporary art and the images that are circulated in its pages, a modernizing look arises, struggling between two strong movements: on the one hand, the more aestheticist option linked to the martinfierrismo vanguard; on the other, the concern for a popular and social art. Between them, the limits and possibilities for a spiritual modernity under the Catholic regime are defined.

KEYWORDs: Criterio, Catholicism, Argentine art, culture magazines.

En sus Recuerdos de la vida literaria, Manuel Gálvez recuerda el surgimiento de la revista católica Criterio en 1928 y divide a sus colaboradores en dos grupos: en primer lugar, aquellos que publicaron en ella, "accidentalmente", como Zorrilla de San Martín, Hugo Wast y Fernández Moreno, junto a otros "señores respetables, buenos creyentes, abogados o médicos" (2003: 15) que satisfacían a las instituciones religiosas y a las monjas asustadizas ante el segundo grupo, desenfadado y juvenil, perteneciente a la nueva sensibilidad. Entre los participantes de este segundo grupo se encontraban los ex-martinfierristas Alberto Prebisch, Emilio Pettoruti, Jorge Luis Borges, Leopoldo Marechal, Francisco Luis Bernárdez y Ernesto Palacio. Si bien Gálvez había anunciado una división bipartita, luego menciona otros dos grupos también presentados en confrontación: los futuros comunistas e izquierdistas (como María Teresa León, Enrique Amorim y Novillo Quiroga) que convivían con los jóvenes y talentosos sacerdotes (Sepich, Meinvielle, Leonardo Castellani, Mario Pinto y Antonio Vallejo ${ }^{1}$. Aisladamente, menciona a Jacobo Fijman y a Julio Finguerit, dos judíos que representaban sin conflicto el espíritu de Criterio. Y, para terminar, él mismo se define como un amigo del grupo a causa de ser el más “viejo” entre los jóvenes colaboradores.

Este esquema que no carece de ironía en la escritura de Gálvez da cuenta de las tensiones sobre las que se asentaba el proyecto editorial de la revista en sus dos primeros años, bajo la dirección de Atilio Dell'Oro Maini $^{2}$, que se traducen en la difusión de un pensamiento católico neotomista que, sin embargo, convive en sus páginas con poemas de escritores vanguardistas, con notas sobre arte moderno y con grabados que circulan desde su portada hasta el interior de los números. Esta suerte de montaje entre tradición y novedad, entre arte popular e innovación estética, que define el funcionamiento de Criterio en su momento inaugural muestra cómo la empresa espiritual que lleva a cabo la juventud católica de la revista permite la convivencia de postulados que podrían asociarse tanto a un régimen estético del arte como a un arte guiado por un modelo de eficacia (Rancière, 2008), ${ }^{3}$ bajo la necesidad de un nuevo orden: el Orden Cristiano. De este modo, si, por un lado, la búsqueda moderna por un retorno al clasicismo tendrá una presencia notoria a través de las 
notas firmadas por Emilio Pettoruti y Alberto Prebisch, por el otro, también se hará presente la afirmación de un arte popular y comunitario en el que el artista se proponga como un artesano, con una función más social que estética. Estas concepciones artísticas, provenientes de tradiciones disímiles, se integran en la construcción de un proyecto cultural católico al que todo le pertenece: lo sagrado y lo profano, lo moderno y lo clásico, el vanguardismo y el realismo, la pureza estética y la mirada social. No se trata, sin embargo, de una síntesis conciliadora, sino, más bien, de apropiaciones que se realizan desde una mirada modernizadora con la intención, al mismo tiempo, de modernizar el catolicismo y liberarlo de la pesada herencia legada por el siglo XIX.

\section{Orden. Criterio y los Cursos de Cultura Católica}

La revista Criterio que sale a la calle por primera vez el 8 de marzo de 1928 tiene una continuidad sostenida hasta el día de hoy. Su frecuencia semanal permitió que el contenido fuera muy actualizado, especialmente en lo que refiere a los debates que se sucedían en Europa acerca de política, economía y arte. En su surgimiento pueden rastrearse dos tradiciones en principio contradictorias. Por un lado, la de una intelectualidad que apuesta fuertemente por un "renacimiento católico" (Di Stéfano y Zanatta, 2000), que buscaba transmitir la doctrina mediante el accionar del laicado en el espacio público, tal como lo había animado en diversas encíclicas el papa Pío XI a lo largo de la década del veinte. En efecto, en la escena intelectual y artísticoliteraria de Argentina resuena una voz católica laica que, en diálogo y tensión con las directrices que se bajan desde el discurso oficial de una Iglesia latinoamericana ya romanizada, busca intervenir activamente en los debates sobre lo moderno. Por el otro, se incorpora en una "red de revistas" (Louis, 2006) culturales y literarias (como Inicial, Proa o Martin Fierro) que manifestaba la necesidad de una renovación estética, una "nueva sensibilidad" que difundiera los aportes de la vanguardia local y europea; ${ }^{4}$ en especial, la importancia dada a la forma y al montaje de tiempos superpuestos. Entre ambas corrientes, Criterio se ubica como un acontecimiento singular que conecta estos ámbitos disímiles, y al hacerlo se posiciona como un órgano de modernización de la retórica católica que debe abrirse a las inquietudes intelectuales y artísticas de su presente. En palabras de Miranda Lida:

Criterio era hija de una década en que las revistas culturales y literarias, imbuidas de vanguardismo, habían vivido una fuerte efervescencia, y no se ahorraría la crítica punzante para con una iglesia que, en aras de masificarse, resignaba sus cualidades intelectuales y artísticas. (...) Criterio se quejaba de que el catolicismo resultaba bastardeado por los propios católicos que pretendían defenderlo, debido a la "mezquina comprensión” de la doctrina, que se difundía popularmente en las parroquias y en la prensa militante para dar por resultado un catolicismo degradado, sin ningún vuelo intelectual o artístico. (Lida, 2014: 114-115)

Este deseo por formar una elite de letrados y artistas católicos se remonta a comienzos de los años veinte cuando se forman los Cursos de Cultura Católica a través de la iniciativa de Tomás Casares, César Pico, Samuel Medrano y Atilio Dell'Oro Maini. Estos Cursos, que se proclamaban como una instancia de formación religiosa, cultural, social y civil, impulsaban la necesidad de que fueran los jóvenes los protagonistas de un cambio espiritual que sólo se podría conseguir, como sostenía Dell'Oro Maini en el discurso de inauguración en 1922, mediante la "cristianización" de la conciencia de la sociedad. En el Programa de Estudios de ese mismo año se lee justamente esta confianza en la juventud y su poder renovador:

Las exigencias de la vida cotidiana desvían a los católicos de su formación esencial, incapacitándolos para el ejercicio de una actuación más positiva y creadora...

Los jóvenes sentimos la necesidad de reaccionar contra esa influencia. Sin sustraernos en absoluto a las exigencias inmediatas, queremos detenernos con seriedad y firmeza en la exigencia perenne y elemental de aprender a discernir certeramente...

Sin la absurda vanidad de alcanzar el dominio perfecto de toda la doctrina, debemos perseguir la posesión de tres elementos indispensables al progreso intelectual en que vamos a empeñarnos: un criterio, una armoniosa visión total y el sentimiento 
agudo de la responsabilidad que entraña nuestra profesión de fe católica. (...) Hasta ahí se limita nuestro primer paso. No fundamos una nueva institución ni labramos estatutos ni agrupamos adherentes: queremos estudiosos sinceros, militantes decididos. (Olazábal, 1986: 24)

Además del Plan permanente de estudios (Filosofia, Historia de la Iglesia y Sagradas Escrituras), también se dictan en los Cursos clases especiales y seminarios de materias afines, a la vez que charlas sobre arte, ciencias y letras. En este sentido, cabe destacar al Convivio, un ateneo de discusión y conferencias, fundado en 1927 como un lugar de encuentro informal, dirigido por César Pico, donde existían también actividades artísticas que iban desde la poesía hasta la plástica (Ghio, 2007: 57-58). Ahí encontramos, entre otros, a los jóvenes escritores y artistas Horacio Schiavo, Leopoldo Marechal, Francisco Luis Bernárdez, Jacobo Fijman (que recibe el bautismo), Tomás de Lara, Antonio Vallejo (que luego tomará los hábitos franciscanos) y Mario Pinto (quien abandonará la crítica cinematográfica para también ingresar en el monasterio, en este caso a la orden de Santo Domingo). Antecedente de Criterio, este cenáculo funcionó como un espacio de sociabilidad en el cual difundir la doctrina católica en conexión con preocupaciones estéticas que excedían el credo religioso.

La apelación a la juventud que Atilio Dell'Oro Maini realizaba en el discurso inaugural de los Cursos de Cultura Católica permite trazar este recorrido que encuentra su momento de clímax en la fundación de esta revista católica que pretende apropiarse del carácter revoltoso de lo juvenil, no ya para romper con la tradición, sino para hacer un corte con el pasado, asociado a una religiosidad mundana que había olvidado sus preocupaciones sobrenaturales. Las lecturas de los filósofos franceses de raigambre neotomista, entre los cuales se destaca Jacques Maritain como intelectual faro, cobra importancia en este renacimiento católico de los años veinte. En esta línea, cabe mencionar el itinerario de Ernesto Palacio que de fundador, colaborador y humorista satírico en la revista Martín Fierro pasa a escribir un artículo - "Proposiciones sobre la crítica"- en el primer número de Criterio, donde proclama la necesidad de restaurar una concepción de la crítica literaria que tenga como fundamento a la filosofía eterna. Palacio acusa a la crítica de haberse subordinado al romanticismo que puso en el centro al hombre como supremo y divino juez, conduciendo de este modo a lecturas idealistas o positivistas de los textos. De este modo, concluye:

La restauración de la crítica no puede venir sino como consecuencia de una restauración más amplia. Exige el restablecimiento previo de las jerarquías espirituales con el reconocimiento consiguiente de la primacía de la inteligencia aplicada a su objeto formal, que es el ser. Debe, pues, fundarse en la filosofía eterna. Solamente el realismo peripatético tomista, con la doble noción de realidad natural y universalidad racional, es capaz de aventar la niebla espesa en que se debate el pensamiento contemporáneo; solamente la inteligencia (cuya función es “discernir al hombre en Callias"), puede distinguir en las obras de arte lo que permanece de lo que varía y, por consiguiente, expresar las condiciones eternas de la belleza. ( $C r i t e r i o, N^{\circ} 1$, 8 de marzo de 1928: 24)

Si pensamos en las revistas como "bancos de pruebas" (Sarlo: 1992: 12) que permiten intervenir en una coyuntura que puede ser política, teórica o estética, en esta glosa que hace Palacio de Art et Scolastique, libro que Maritain publica en Francia en 1920, se deja ver la construcción de un imaginario común que, legado por los Cursos de Cultura Católica, atraviesa Criterio: el retorno al orden. En efecto, en la página inicial del primer número de la revista aparece un editorial titulado "La Inteligencia" (Criterio, N 1, 8 de marzo de 1928: 9-10) donde se desliza el programa que guiará la publicación y que puede leerse en sintonía con el texto de Palacio. Ahí se hace un diagnóstico del presente, más exactamente de la "agitación contemporánea” que se vislumbra al vivir en un "mundo arrancado de su quicio", promoviendo como salida la restauración de jerarquías y el restablecimiento de una visión objetiva. Ambos criterios estarían subsumidos en la primacía de la función intelectual que consistiría "en desentrañar la esencia de las cosas hasta alcanzar la visión de toda la realidad en su orden propio” (Idem), orden dado por la ley de Dios, para afrontar así tanto al liberalismo como al avance de "las izquierdas" en el mundo actual. Pero este orden, que es social, encontrará su potencialidad estética en la propuesta de un arte constructivo, clásico y puro que espiritualice los ímpetus anárquicos que legaron las experimentaciones vanguardistas. 


\section{Clásico y moderno. Pettoruti y Prebisch en Criterio}

En el cuarto número de Criterio, Emilio Petorutti participa de la sección "Notas de Arte" con "Pintores del 900 italiano", que sugiere la entrega de distintos artículos sobre las figuras más representativas de este movimiento de arte conocido como Grupo Novecento, liderados por Margherita Sarfatti. No obstante, sólo tres pintores son presentados en marzo, abril y junio de 1928: Piero Marussig, Mario Tozzi y Hugo Bernasconi. Sobre el primero, Petorutti se detiene en su biografía, en su recorrido académico en Roma y París y en su instalación en Milán donde define su personalidad pictórica. Leemos:

Descartadas las tendencias y los programas es conveniente agregar que sería erróneo afirmar por consiguiente, que Piero Marussig se haya extraviado en los movimientos que se han producido en el campo de la pintura contemporánea; lo justo es asegurar que los ha sentido y determinado, asimilándolos a su visión.

Su caso es singular por la razón que sus obras tienen por un lado el acento sutil de las audacias de nuestro tiempo, mientras que por el otro se presenta bajo el aspecto más simple y se aparece, hoy, compuesto en un orden tradicional.

He aquí lo que lo distingue y lo impone. ( Criterio, N4, 29 de marzo de 1928: 119).

Preocupado por ubicar esta búsqueda estética lejos de cualquier interpretación reaccionaria, Petorutti presenta a Marussig como un artista capaz de hacer confluir lo audaz moderno con el orden tradicional. Esta tendencia pictorica que había nacido en Roma en 1918 alrededor de una revista llamada Valori plastici, que el artista argentino conoce en su estadía en Italia,tenía como propósito aunar cierta tradición italiana (la de Giotto, Masaccio y Piero della Francesca) con el lenguaje figurativo moderno (el de Cézanne y el cubismo), para lograr así un arte moderno que tuviera al mismo tiempo una preocupación metafísica acerca de la identidad nacional (entre otros participantes del movimiento podemos citar a De Chirico, Carrá, Arturo Martini y Giorgio Morandi). Posteriormente, en 1922, esta experiencia será continuada por el grupo milanés Novecento, que tendrá como lema la lucha contra los excesos de la vanguardia que había rotos sus vínculos con la historia nacional, mediante un retorno al clasicismo de la época de Augusto, que conlleva un estilo monumental y solemne, en sintonía con el incipiente fascismo.

El artículo de Pettoruti ya había sido publicado un año antes en la revista Crítica Magazine, suplemento del diario Crítica, enemigo de la revista católica, que tenía una sección sobre arte contemporáneo en la que se difundía "la vanguardia estética explicada al alcance de todos, con reproducciones de cuadros y dibujos de los artistas mencionados" (Saítta, 1998: 175). ¿Cómo leer entonces la reaparición de la semblanza en este nuevo contexto de enunciación? Si bien esta poética centrada en el de regreso a lo clásico no posee en la nota de Pettoruti ninguna adscripción religiosa, dentro de la revista católica se resignifica en el diálogo con el llamado rappel à l'ordre que se hace presente, en el mismo número, a través de una reseña sobre Jean Cocteau, que sucede inmediatamente al texto del pintor argentino. El pequeño artículo trata sobre la adaptación libre y moderna que hizo el escritor francés de las obras clásicas Edipo Rey de Sófocles y Romeo y Julieta de Shakespeare. Cocteau que ya había realizado su conversión al cristianismo a través de la influencia de Jacques Maritain y había publicado su famoso libro Le rappel à l'ordre en 1926, en consonancia con el "Rappel á l'intérieur" del abate Bremond ${ }^{5}$, llama a la simplicidad y a la vuelta a un orden clásico. Como explica Sergio Baur, el Novecento italiano fue leído por la crítica de arte como un antecedente insignificante del rappel à l'ordre, y esta vuelta al orden suponía un regreso al clima clasicista que se podía comprobarse en las "impresionantes arquitecturas" que servían de fondo a los cuadros de estos artistas, ya que "el arquitecto y más aún el ingeniero son los sujetos recurrentes de esta otra modernidad, más técnica y de naturaleza autónoma" (2010:103). Pero esta apuesta por lo técnico no se contradice con la voluntad de espiritualización que reclama el catolicismo. De hecho, en su libro Arte y escolástica, al que ya hicimos referencia, y que constituye por esos años el faro cultural de la juventud católica, Maritain va a rescatar a Le Corbusier y al cubismo, ya que ambos se oponen a una reproducción imitativa de lo real y enfatizan el carácter constructivo del arte, bajo una lógica propia y misteriosa, casi viviente, que depositan en las obras. Lo que sí criticará el filósofo francés son las ideas sobre lo útil de Le Corbusier, que deberían desvanecerse en la opción por una 
armonía matemática que permita un arte "bello" y desinteresado. En su propuesta anacrónica por buscar en el presente las condiciones espirituales legadas por la Edad Media, la mirada de Maritain no rechaza de por sí la experimentación moderna, aunque selecciona los aciertos y corrige lo que se desvía de su concepción estética católica a mitad de camino entre Santo Tomás y Baudelaire. De esta manera, el montaje entre técnica y espíritu permitirá que la arquitectura se posicione como un lenguaje central en el moldeado de una poética católica que enfatice la rigidez del aspecto compositivo de la creación literaria.

La apertura que se lee en Criterio acerca de esta tendencia de regreso a un orden clásico, también se comprueba en relación con el arte argentino, en especial con los artistas vinculados al Grupo París, sobre los que escribe Alberto Prebisch. No obstante, el interés sobre el arte argentino contemporáneo no queda tan sólo en las páginas de la revista, sino que también se integra a las actividades de los Cursos de Cultura Católica. Así, en el número 11, del 17 de mayo de 1928, se publica en la sección "Vida intelectual" la crónica de la inauguración anual de los Cursos, que contó con una misa en el Templo de San Juan y también de una ceremonia en la sede de la calle Alsina. Ahí Tomás Casares da inicio al ciclo lectivo exponiendo el plan de estudios para ese año y el Nuncio de S.S, monseñor Felipe Cortesi, comunica que el nuevo salón de exposiciones de los Cursos contaría con las telas de Norah Borges, Emilia Bertolé, Adolfo De Ferrari, Juan Antonio Spottorno, José Bonomi, Emilio Pettorutti, Lino Palacio y otros. El anuncio de la incorporación de Prebisch se realiza el 9 de agosto de 1928, en el número 23, en una nueva sección "Itinerarios", donde se informa que en "Amigos del Arte" se inauguró una exposición con cuadros de los pintores Aquiles Badi, Héctor Basaldúa, Antonio Berni, Horacio A. Butler, Lino Spilimbergo y Juan del Prete, a la vez que se invita a la conferencia que dará Prebisch sobre "las orientaciones de la pintura contemporánea" (1928: 166). Dos semanas después aparecerá bajo el título "Exposiciones" ( Criterio, N²5, 23 de agosto de 1928: 249-250) el análisis de Prebisch sobre esta primera muestra conjunta que reúne a los seis jóvenes pintores mencionados anteriormente. Deteniéndose en cada uno de ellos, destaca en rasgos generales el privilegio de lo plástico por sobre la representación del motivo. Así, en Horacio Butler rescata su tendencia imaginativa y lírica, junto con su ambición monumental, en el sentido clásico que no refiere al tamaño material de la tela, sino "a cierto concepto generoso, sumario y arquitectónico de la forma”. A Butler se lo define por un lirismo plástico, a Héctor Basaldúa se lo liga con el lirismo poético, es decir, con "la interpretación poética de las cosas" más cerca del celebrado pintor uruguayo Pedro Figari, aunque más "fantasista" (sic) e imaginativo. Sobre el joven Antonio Berni, se manifiesta negativamente una preocupación por su "constante mariposeo", por su activa curiosidad que lo lleva del sobrerrealismo expresionista, al cromatismo estridente y casi abstracto, pasando por la influencia de Picasso y el neoclasicismo. En contraposición, a Lino Spilimbergo se lo muestra con una clara obsesión por las formas simples y bien estructuradas, aunque falte expresar todavía "una efectiva solidez interna". Por último, Juan del Prete es definido por una frenética necesidad expresiva que excede cualquier designio teórico y se vincula con la exigencia de una pintura pura. Frente a estos representantes del arte argentino moderno, se recorta un enemigo común que aparece bajo la figura del pintor Cesáreo Bernaldo de Quirós, quien protagoniza la siguiente entrega de "Exposiciones". Este artículo se destaca porque la pluma de Prebisch no solamente critica negativamente la obra de Quirós, sino que expone su propia concepción estética que, como mencionamos, apela a la síntesis plástica y a la despreocupación por lo temático:

La ausencia del episodio no afecta en nada el fondo de una creación plástica. Si yo reprocho al arte del señor Quirós su marcada inclinación anecdótica, no lo hago en nombre de una tendencia o de una escuela. Pero sí en nombre de la pintura, que mantiene sus básicas leyes inmutables a través de todas las épocas. Pero he hablado de mala fe, y voy a justificar mi aserto. Cuando una obra no se basta por sí misma, tiende indefectiblemente a extraer del asunto que la informa, y de ciertos accesorios efectistas, toda su significación emocional. La mala pintura repite así los divulgados procedimientos del teatro plebeyo: músicas lejanas entre bastidores, llantos incontenidos, escenas truculentas. El efecto es seguro y descontado de antemano por un autor que conoce bien las debilidades de su público. Y no se puede negar la pericia del señor Quirós en el manejo adecuado de análogos expedientes. Pero en vano buscaremos en sus cuadros un solo trozo que denote una auténtica sensibilidad pictórica. ( Criterio, N²6, 30 de agosto de 1928: 280) 
Dos declaraciones de Prebisch pueden ponerse en serie con las notas de arte escritas por Pettoruti: por un lado, la imperiosa necesidad de desligarse de cualquier filiación a un movimiento o escuela de vanguardia, sosteniendo la importancia de la voz propia no subsumida a un colectivo; por el otro, la opción por pensar lo pictórico a través de reglas clásicas y eternas que ordenen la composición a través de un imperativo plástico no subordinado al contenido anecdótico. Asimismo, Prebisch retoma un tema que ya había sido explorado con preocupación en las páginas de Martín Fierro, las limitaciones del público porteño que, en este caso, se lo muestra fácilmente coaptado por los recursos efectistas y sentimentalistas usados por Quirós en sus cuadros. Pero esta tarea de educar al espectador tomará un nuevo rumbo en las páginas de Criterio, ya no se trata tan sólo de seguir guiándolo en la apropiación de los nuevos lenguajes pictóricos, pues ahora se pone en juego también otro tipo de recepción: la religiosa. En el número 29, diciembre de 1928, Prebisch se detiene en la muestra del Fray Guillermo Butler que estaba teniendo lugar en la Asociación Amigos del Arte para advertir sobre la diferencia entre dos tipos de pintura religiosa que no deben confundirse: una, sentimental y no sensible, antiplástica, representada por los cuadros del padre Butler, y otra, más objetiva, donde la emoción estética se sostiene por medio de relaciones cromática y formalmente precisas, con independencia de la existencia del artista, consiguiendo así una armonía y una realización de lo absoluto. La emoción no pasaría entonces por una cuestión subjetiva ante el tema representado, sino por su propia autonomía como objeto estético. Lo religioso en esta definición resta, ya que el arte se evadiría de cualquier atributo externo a su constitución:

Pero yo estoy definiendo -y ya se habrá percatado de ello el lector- no una especie de pintura religiosa, sino, pura y simplemente, la Pintura. Y es que la pintura, y el arte todo, considerado como un "objeto" y no como una vaguedad sentimental, entran fácilmente dentro de las tradicionales normas católicas. (Alguien ha notado ya la equivalencia evidente entre la armonía de las formas y la lógica del dogma). Así la pintura religiosa, -y especialmente católica- no está en el tema que la informa, sino en el espíritu que la anima y le presta vida propia e independiente. ( Criterio, $\mathrm{N}^{\circ} 26,30$ de agosto de 1928: 377)

Lejos de lo sublime como exaltación de una emoción religiosa, y más cerca de la autonomía de un arte compositivo que se da sus propias reglas, se puede establecer un diálogo entre el arte moderno y el catolicismo que impulsa la revista Criterio, ya que ambos poseen en común la convicción de una necesidad de ordenamiento que se dé a través de la primacía de las formas, y no del sentimiento -inspirado por lo estrictamente temático. ¿Pero cómo evangelizar sin apelar a los símbolos universales que conducen a una creencia religiosa? Para esto se hará necesario introducir otros materiales visuales y otras reflexiones sobre el arte y su vínculo con la sociedad.

\section{Pueblo. Las imágenes religiosas en Criterio}

Como revista cultural, Criterio no sólo presenta una mirada atenta a las novedades bibliográficas y artísticas del momento, sino que también ostenta un marcado interés por la reproducción de imágenes que establezcan un diálogo con el contenido de la publicación. Desde las xilografías de Juan Antonio Spotorno que se reproducen en la portada y también acompañan la editorial, hasta las ilustraciones que se intercalan en las páginas de algunos números de la revista (con firmas de Lino Palacio, Norah Borges, Bonomi, Daniel M. Agrelola, Víctor Delhez), la imagen y su materialidad le sustrae a lo religioso su carácter aurático y lo reviste de modernidad. Con las xilografías y las aguafuertes de estos artistas, Criterio se ubica dentro de una tradición gráfica que sostiene la posibilidad del grabado como técnica de reproducción y difusión de la imagen, que adquiere una circulación ampliada y un consumo masivo. Como explica Silvia Dolinko en su libro Artepara todos:

Si la presencia de las artes plásticas dio apoyo o anclaje visual a los planteos sostenidos desde los textos -orientados muchas veces a cuestiones políticas o literarias-, a la vez, la inclusión en las publicaciones de la obra de los artistas gráficos posibilitó la circulación de imágenes en una mayor escala cuantitativa, potenciando la multiplicidad inherente al grabado. De este 
modo, se amplió el consumo de esta producción visual por fuera de los límites convencionales del sistema artístico ortodoxo, circunscripto a museos, salones y galerías de arte (2003: 20)

Pero en el caso de Criterio lo que vemos es que la circulación y consumo de imágenes se encuentra dirigida a sostener el espíritu religioso que sustenta el proyecto editorial de la revista, como se comprueba en "Niña vestida de primera comunión" de Norah Borges ( Criterio, N¹0, 10 de mayo de 1928) [Fig. 1], "San Juan, niño" de Bonomi ( Criterio, N 11, 17 de mayo de 1928) [Fig. 2], "Alegría de vivir" de Juan Antonio ( Criterio, N³1, 4 de octubre de 1928) [Fig. 3] o "Excmo. Arzobispo de Buenos Aires Mons. Fray José María Bottaro" de Víctor Delhez ( Criterio, N³8, 8 de noviembre de 1928) [Fig. 4].

Figura 1

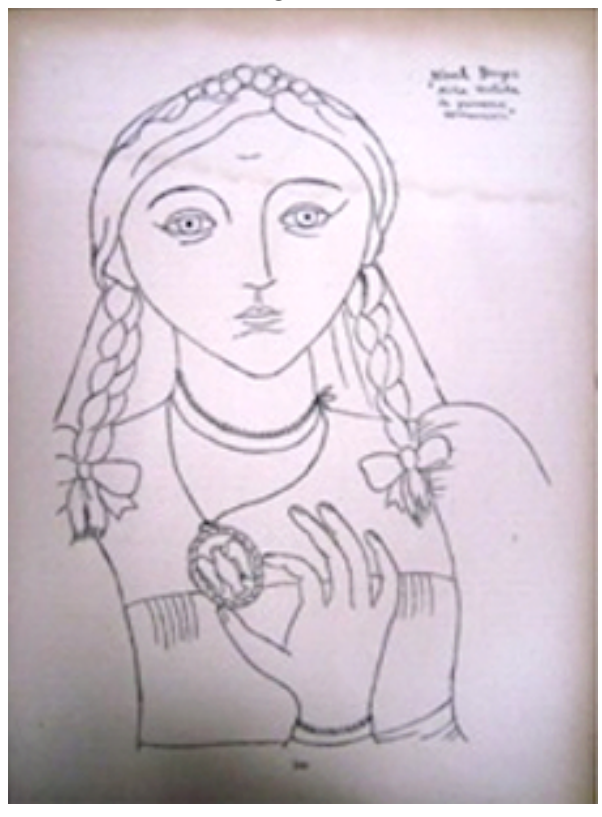

Figura 3

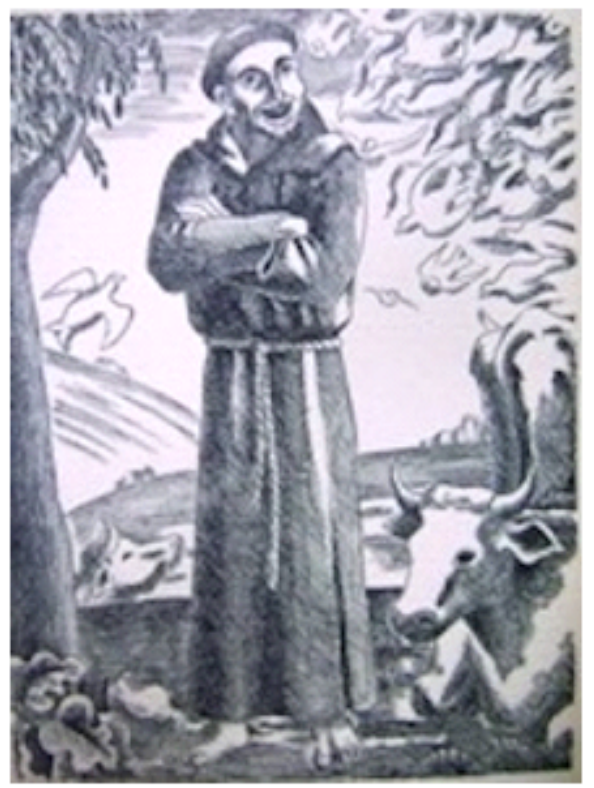

Figura 2

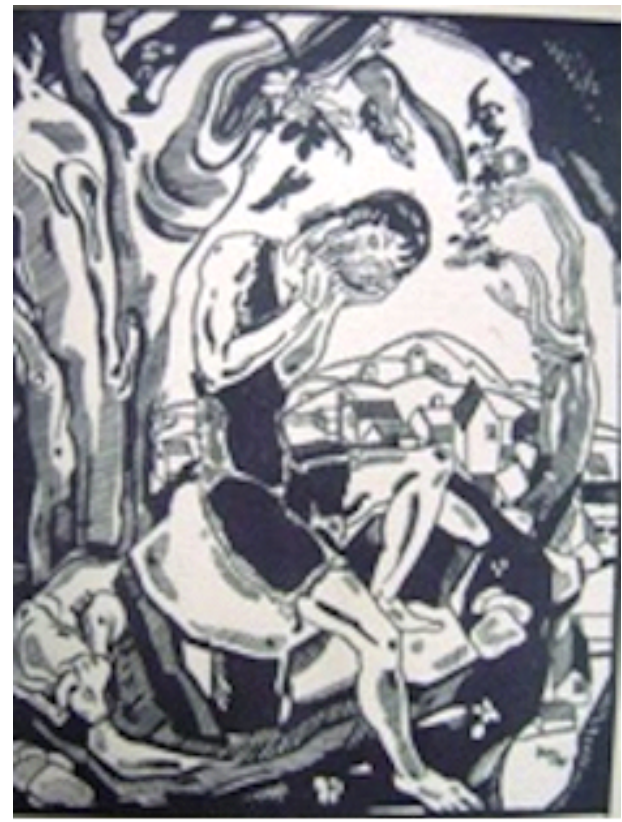

Figura 4

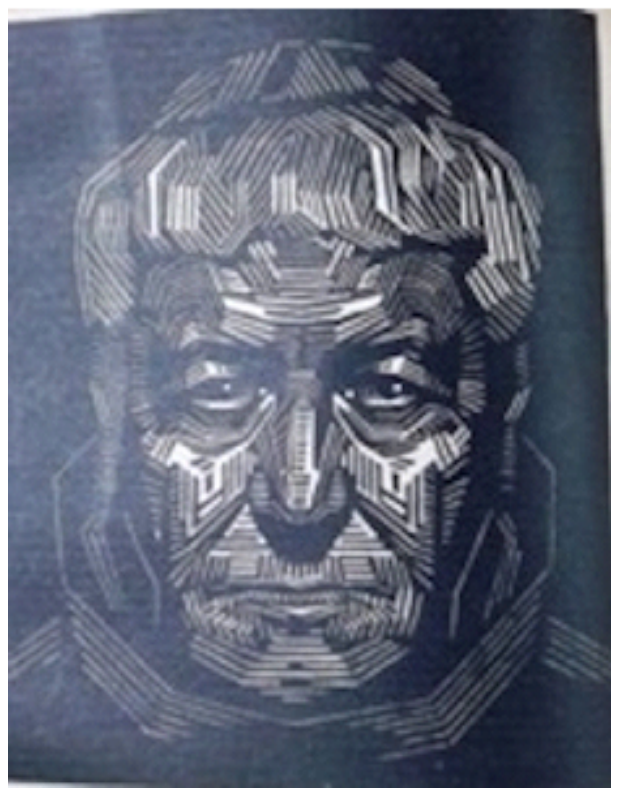


Mientras que en sus columnas Prebisch recorría las exposiciones que se daban en Buenos Aires mostrando las obras de arte de los jóvenes pintores modernos, aquí vemos cómo Criterio constituye una suerte de galería del grabado nacional bajo diferentes técnicas (el dibujo, la xilografía, el aguafuerte) que dan cuenta también de lo que se está produciendo en el campo artístico del momento, pero en general apelando, ahora sí, al motivo religioso como modo de acercar los símbolos y figuras del catolicismo al público. Esto se ve claramente en las imágenes de portadas que realiza Juan Antonio Spotorno. Los primeros diecisiete números contienen relecturas de episodios bíblicos que en general remiten al Nuevo Testamento (la Resurrección, la multiplicación de los Panes, la entrada triunfal en Jerusalén, la aparición a los discípulos, la Ascensión, el Pentecostés, entre otros) y se acompañan de versículos (en la reproducción del sumario) que guían al lector en el universo del cristianismo. Como podemos ver en el número 3, del 22 de marzo de 1928 [Fig. 5, 6 y 7].

Figura 5

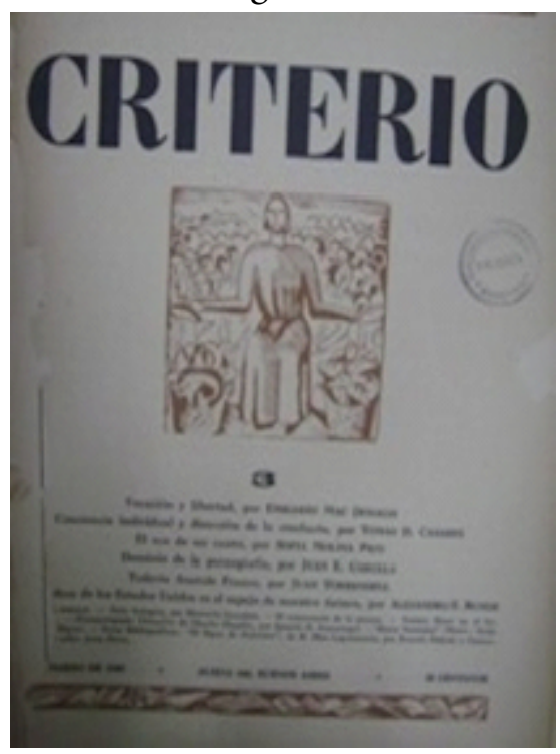

Figura 6

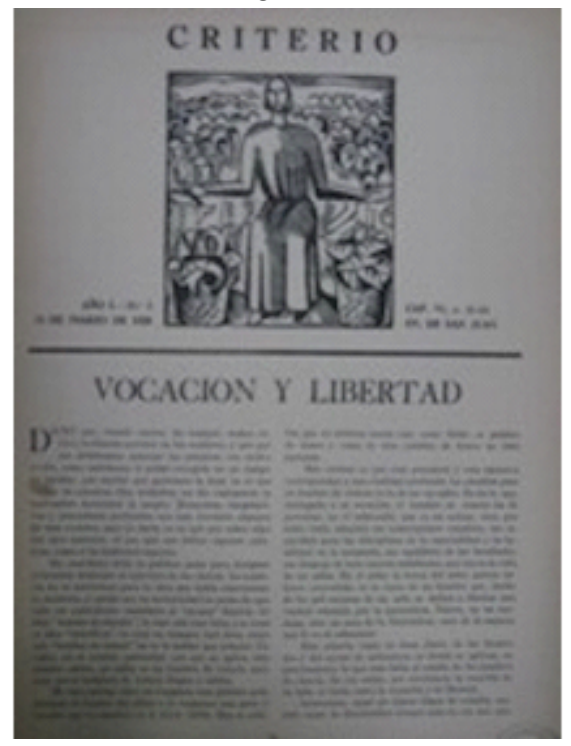

Figura 7

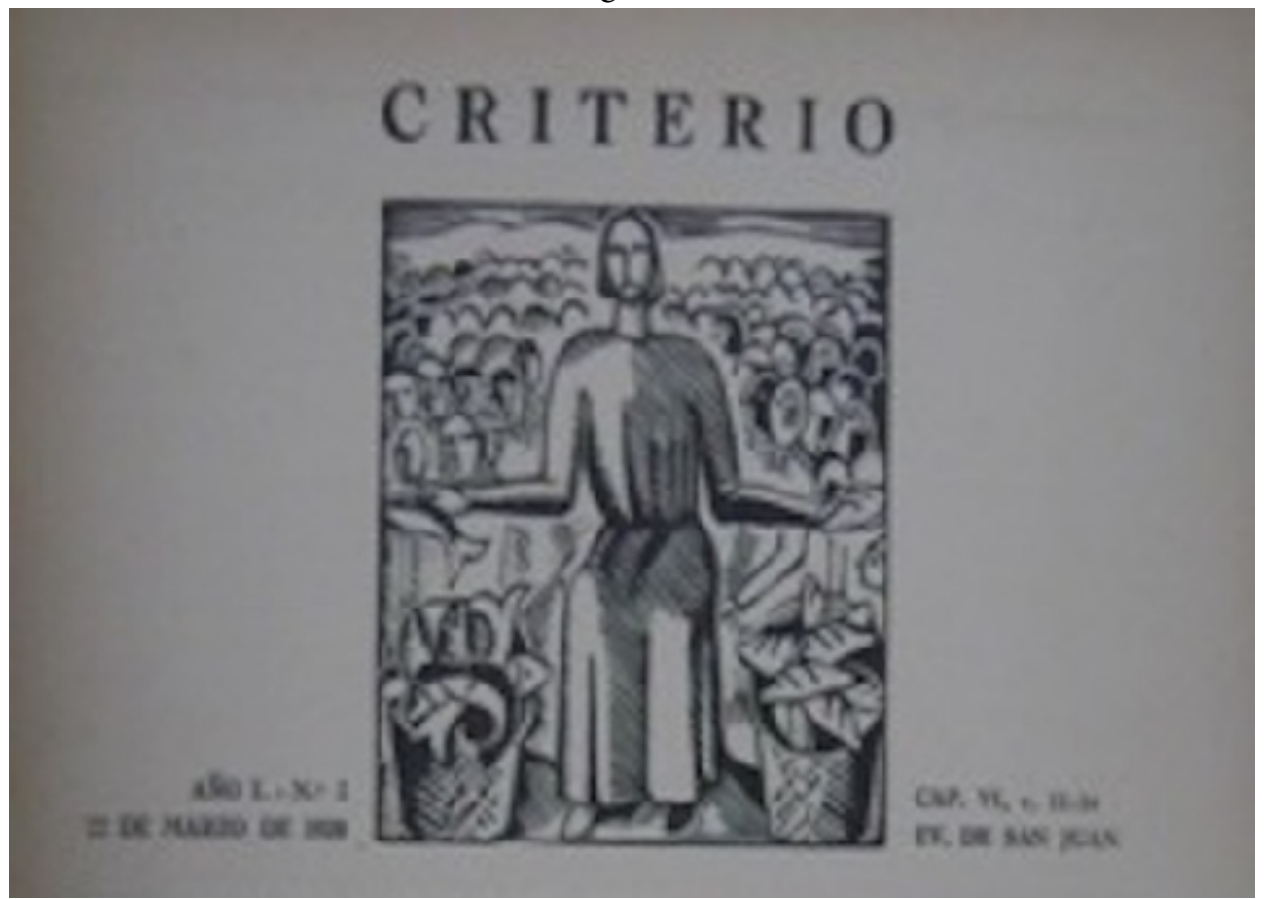


La técnica moderna se pone al servicio de un mensaje religioso. Estos primeros números ilustran la necesidad de una "nueva cristiandad" que debe impregnar en el tejido social combatiendo los intentos por secularizar los campos intelectuales y estéticos de la Argentina de comienzos del siglo XX. ${ }^{6}$ De este modo, son recurrentes las imágenes vinculadas a Cristo y a sus discípulos como ideal de una comunidad que venga a espiritualizar un presente leído en términos catastróficos como materialista y desencantado, en el que avanza el peligro rojo del comunismo disolvente. Si el arte, en este sentido, debe dar cuenta de este intento de sacralización de las esferas sociales y la vida cotidiana, una pregunta sobrevuela las páginas de la revista: ¡cómo conciliar el arte moderno y su pretensión de autonomía estética con la necesidad de que este cumpla también una función social?

Este interrogante no se resolverá en esta primera etapa de Criterio, sino que ambas concepciones estéticas convivirán en tensión en sus páginas. En el número 31, del 4 de octubre de 1928, la crítica de arte italiana Eva Tea escribe una reseña sobre la semana artístico-litúrgica organizada por los "Amigos del Arte Cristiano" y de la "Escuela Beato Angélico" ${ }^{7}$ en Milán, donde justamente plantea el problema de un "arte útil”. Leemos:

Estamos desde hace demasiado tiempo, acostumbrados a contemplar en el arte la simple efusión del artista o el deleite del espectador, para que la idea de una servidumbre artística no deba parecernos anticuada y absurda.

Y bien: la gran cuestión del arte religioso finca toda aquí. ¿Está dispuesto el artista a servir al sentimiento de su pueblo frente al más alto problema de la vida humana? Si consiente, producirá verdadero arte sacro; en caso contrario, tendremos simples efusiones o místicas o líricas o pictóricas, profanas siempre de inspiración, cuando no decididamente heréticas, como frecuentemente hoy ocurre. ( Criterio, $N^{\circ} 31,4$ de octubre de 1928: 19)

Lo que se pone de relieve en esta cita refiere a la posibilidad y a los límites de un arte sagrado al servicio del pueblo en el mundo moderno. En sus xilografías, Juan Antonio Spotorno, que años más tarde, en 1932, junto con Juan Antonio Ballester Peña fundaría un Taller de Arte Cristiano en San Cristóbal, contempla esta problemática en torno a la salida de la efusión individual del artista hacia lo colectivo y popular. Carentes de su propia firma (recién en el número 18 aparecerá su nombre en el sumario), las imágenes se inscriben en el soporte revista con cierta función didáctica: la espiritualización de las masas mediante la opción por un arte que conjuga las técnicas modernas con el anonimato y la artesanía.

La idea del artista como artesano es un tópico muy presente en Criterio, especialmente a través de la figura de Maritain y de Berdiaeff, quienes encontraban en el Medioevo una concepción comunitaria y orgánica del trabajo, no atravesado por la maquinización, la racionalización y la división de tareas. En el número 3, donde aparece, como se muestra arriba, la imagen de Cristo y la multiplicación de los panes, se encuentra un artículo sobre la relación entre trabajo y cristianismo. Ahí se festeja al obrero medieval quien, al ubicarse por fuera de la lógica capitalista, se define como un artífice que produce impulsado por una ley vital y se agrupa en corporaciones fundamentadas por el amor y la alegría de producir, y no por resistencias y reivindicaciones sociales:

La palabra reinvindicación no existe para el artesano aquel. Sólo aparecerá en el vocabulario del trabajo, cuando el trabajo pierda su sentido cristiano y cuando la filosofía de la historia se trueque de espiritualista en materialista. Cuando Marx introduzca su "Das Kapital", como una cuña en la vida humana. ( Criterio, №3, 22 de marzo de 1928: 80)

Esta necesidad de reactualizar una época no marcada por la lógica moderna se verá reforzada no sólo con diversos artículos de Ernesto Palacio, César Pico y Tomás de Lara, sino también con los cambios de temáticas en las imágenes de Spotorno. En efecto, luego del número 17 se abandona el tópico bíblico (junto con las citas de los Evangelios) y se presenta una serie que tiene que ver con las distintas artes (Geometría, Música, Pintura, Arquitectura, Alfarería, Cinematógrafo, Imprenta, Oratoria, Escultura, Geografía, Ballets), a la que le sigue las profesiones (Herrero, Albañil, Carrero, Jardinero, Lechero, Pescador, Cura, Cazador, Comerciante, etc.), y en 1929 aparece una temática más heteróclita, aunque en su mayoría vinculada con el mundo rural. Asimismo, cada serie tendrá su propio color y su propia banda ornamental, como mostramos 
a continuación: Criterio, №6 (12 de abril de 1928), №10 (10 de mayo de 1928) y №14 (7 de junio de 1928)[Fig. 8]; Criterio No18 (5 de julio de 1928), №20 (19 de julio de 1928) y No27 (6 de septiembre de 1928)[Fig. 9]; y Criterio $\mathrm{N}^{\circ} 31$ (4 de octubre de 1928), $\mathrm{N}^{\circ} 36$ (8 de noviembre de 1928) y N 53 (7 de marzo de 1929) [Fig. 10]. Si bien entre estos temas profanos se inserta algún número que presenta motivos religiosos, como la ilustración de Santa Rosa de Lima, de Santa Cecilia, de Navidad o de Cristo Crucificado, la portada de la revista se seculariza visualmente desde julio de 1928.

Figura 8

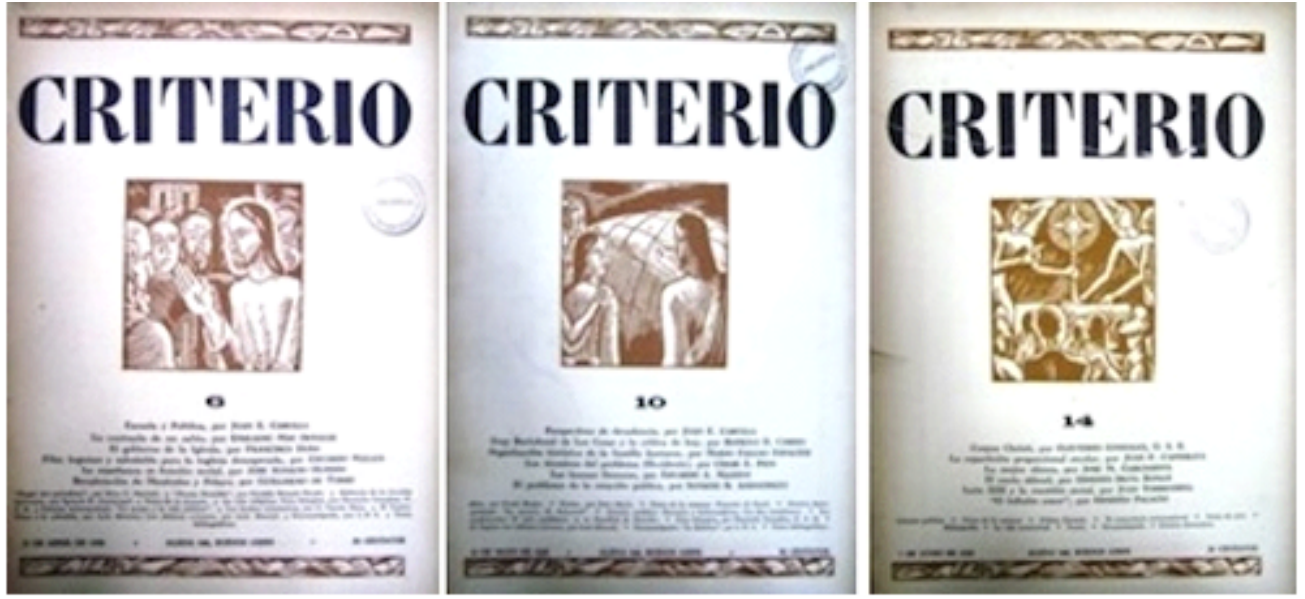

Figura 9
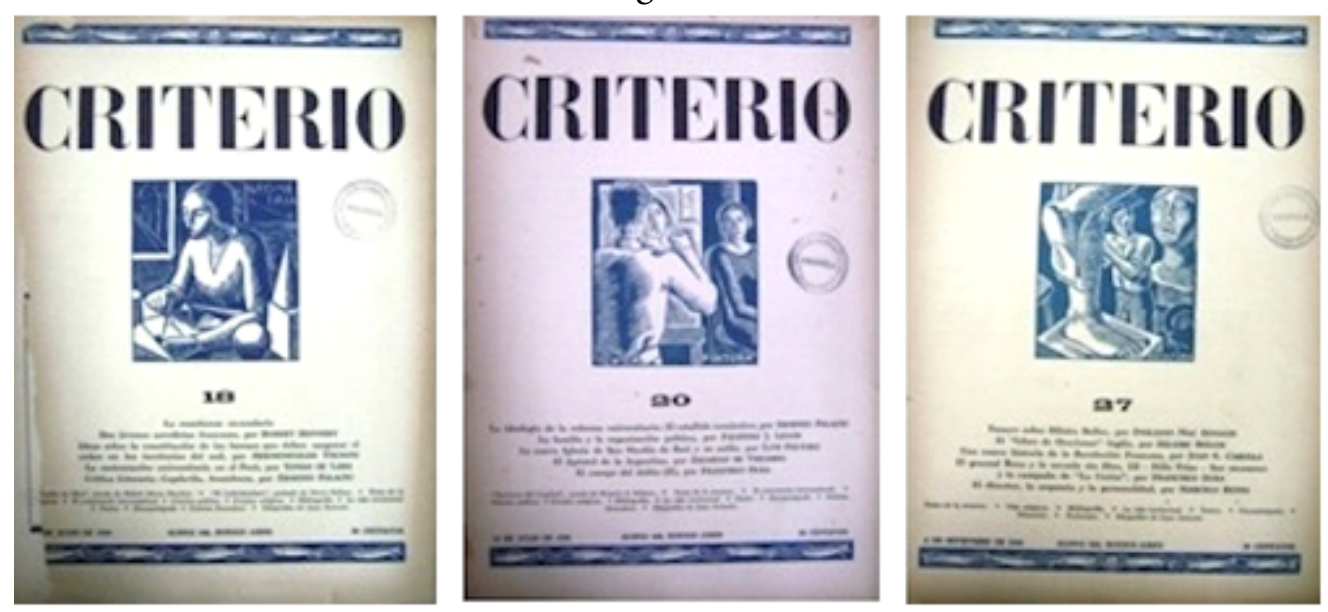

Figura 10
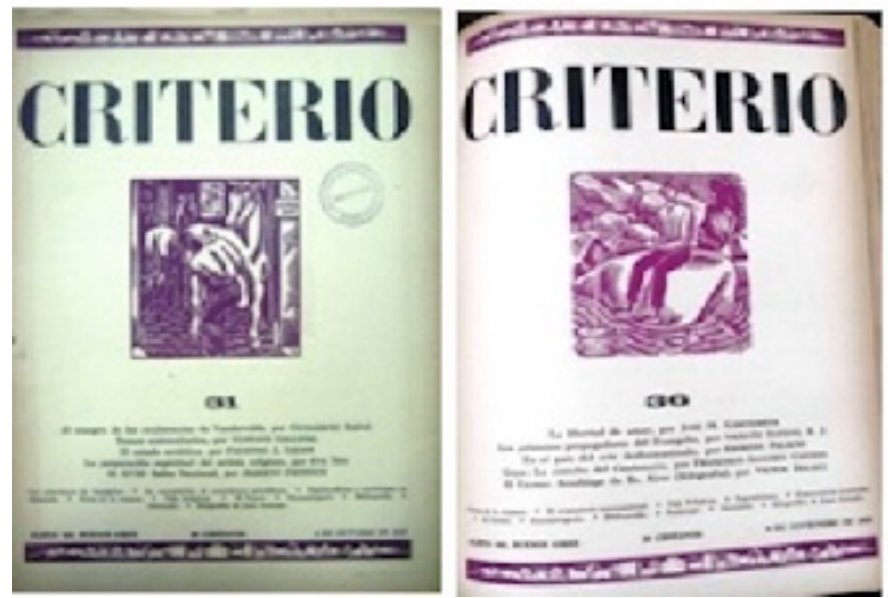
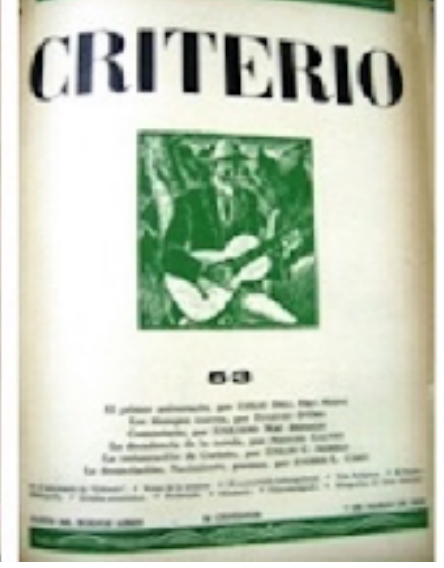
Así, desde la elección por el estilo dibujístico, que enfatiza las líneas y los contornos (en la tradición legada por Durero), las imágenes de las portadas proponen un arte popular que conlleva una visión idealizada del pueblo a través de la mitificación del mundo artesanal y rural. Esta operación sacralizante disputa con el programa antiliberal del socialismo y del comunismo, ya que también aboga contra el utilitarismo capitalista; sin embargo, acá la mirada se nutre de la nostalgia por un comunitarismo corporativo. Podríamos pensar las xilografías de Spotorno como la traducción visual de la concepción artística de esta filosofía medieval, actualizada por el neotomismo francés, mediante el borramiento de las divisiones entre artes manuales y bellas artes, ideando un ideal de obra colectiva, junto con el regreso utópico al ámbito natural, donde la civilización no ejerció sus vicios. Lo religioso así se traslada de lo estrictamente temático hacia un orden espiritual: el mito por una sociedad más armónica, sin clases, pero sustentada por la jerarquía del orden sobrenatural que le quita al presente la primacía corrosiva de lo material y lo utilitario.

De este modo, signada por un catolicismo incipiente, que luego tomará fuerza y poder a lo largo de la década del treinta, este primer período de Criterio delinea la puesta en marcha de un proyecto de modernidad espiritual, en la que ingresan los lenguajes artísticos que se están desarrollando en un presente secularizado que, sin embargo, no deja de preguntarse por el costado metafísico de la existencia. Entre la forma del arte y el arte social, la potencia de lo actual desestabiliza las doctrinas conservadoras, y cuando esto se perciba, la revista tomará otro camino, vinculado con las directrices del catolicismo papal bajo la Acción Católica, en el que ya no habrá más lugar para estas problemáticas estéticas contemporáneas.

\section{FUENTES}

"La Inteligencia". Criterio, N 1,8 de marzo de 1928, pp. 9-10.

"Itinerarios". Criterio. $\mathrm{N}^{\circ} 23,9$ de agosto de 1928.

"Notas bibliográficas". Criterio, N4, 29 de marzo de 1928, p.120.

"Vida intelectual". Criterio. $\mathrm{N}^{\circ} 11,17$ de mayo de 1928.

Bonomi. “San Juan, niño". Criterio, N¹1, 17 de mayo de 1928, p. 332.

Borges, Norah. "Niña vestida de primera comunión". Criterio, N¹0, 10 de mayo de 1928, p. 300.

Delhez, Víctor. “Excmo. Arzobispo de Buenos Aires Mons. Fray José María Bottaro”. Criterio, №38, 8 de noviembre de 1928, p. 172.

Delhez, Víctor. "El individualista". Criterio, N¹8, T.2. 5 de julio de 1928, p. 12

Delhez, Víctor. "Cables”. Criterio, N51, 21 de febrero de 1929, p. 246.

Juan Antonio. “Alegría de vivir”. Criterio, N³1, T.2, 4 de octubre de 1928, p. 14.

M. A. E. "El sentido cristiano del trabajo". Criterio, N³, 22 de marzo de 1928, p. 79.

Marechal, Leopoldo. "Retruque a Leopoldo Lugones" Martín Fierro, núm. 26, diciembre de 1925, p. 2.

Palacio, Ernesto. "Proposiciones sobre la crítica". Criterio, No 1,8 de marzo de 1928, pp. 23-24.

Palacio, Ernesto. "Estética nihilista”. Criterio, N5, 3 de abril de 1928, pp. 150-152.

Pettoruti, Emilio. "Pintores del 900 italiano". Criterio, N4, 29 de marzo de 1928, p.119.

Pettoruti, Emilio. "Pintores del 900 italiano. Mario Tozzi" Criterio, N7, 19 de abril de 19928, p.215.

Pettoruti, Emilio. Un pintor ante el espejo (1968). Buenos Aires: Sudamericana.

Prebisch, Alberto. "Exposiciones: Los pintores jóvenes”. Criterio, N²5, 23 de agosto de 1928, pp. 249-250.

Prebisch, Alberto. “Exposiciones: Cesáreo B. de Quirós (Amigos del Arte)". Criterio, №26, 30 de agosto de 1928, p. 280.

Prebisch, Alberto. "Exposiciones. Fray Guillermo Butler (Amigos del Arte)”. Criterio, N²6, 30 de agosto de 1928, p. 377

Tea, Eva. “La preparación espiritual del artista religioso". Criterio, N³1, 4 de octubre de 1928, p. 19. 


\section{BIBLIOgRAFÍA CITADA Y CONSULTADA}

Adur, Lucas (2010). "Entre la Iglesia y la vanguardia. Un análisis del manifiesto de la revista Criterio, órgano del 'renacimiento católico' argentino". En: Discurso. Teoría y análisis 30, pp. 59-79. Disponible en: http://www.discoursescience.info/wp-content/uploads/03adur.pdf

Alcalá, May Lorenzo y BAUR, Sergio. Pettoruti crítico en Crítica. Buenos Aires, Patricia Rizzo Editora, 2010.

Artundo, Patricia (dir.) (2008). Arte en revistas. Buenos Aires: Beatriz Viterbo.

Badiou, Alain (2009). El siglo. Buenos Aires: Manantial.

Bürger, Peter (2010). Teoría de la vanguardia: Las cuarenta.

Delgado, V.; Mailhe, A. y Rogers, G., (coords.) (2014). Tramas impresas: Publicaciones periódicas argentinas (XIX$X X)$. La Plata: Universidad Nacional de La Plata. Facultad de Humanidades y Ciencias de la Educación. Estudios-Investigaciones; 54. En Memoria Académica. Disponible en: http://www.memoria.fahce.unlp.ed u.ar/libros/pm.376/pm.376.pdf

Dolinko, Silvia. Arte para todos. La difusión del grabado como estrategia para la popularización del arte. Buenos Aires, Fundación Espigas, 2003.

Devoto, Fernando. (2005). “Atilio Dell'Oro Maini. Los avatares de una generacio\#n de intelectuales cato\#licos del centenario a la de\#cada de 1930", in Prismas - Revista de Historia Intelectual, nu\#m. 9, 2005, pp. 187-204.

Devoto, Fernando. (2006) Nacionalismo, fascismo y tradicionalismo en la Argentina moderna. Una historia. Buenos Aires: Siglo XXI Editores.

Di Stefano, Roberto y ZANATTA, Loris (2000). Historia de la Iglesia argentina. Buenos Aires: Mondadori.

Gálvez, Manuel (2003). Recuerdos de vida literaria (II). Entre la novela y la historia. En el mundo de los seres reales. Buenos Aires: Taurus.

Ghio, José María (2007). La Iglesia católica en la politica argentina. Buenos Aires: Prometeo.

Gilman, Claudia (2006). "Florida y Boedo: hostilidades y acuerdos". En: MONTALDO, Graciela (comp.). Irigoyen entre Borges y Arlt. Buenos Aires: Paradiso.

Jesús, Lorena. "Católicos y nacionalistas en los orígenes de la revista Criterio, 1928-1930". En: historiapolitica.com. Disponible en: http://historiapolitica.com/datos/biblioteca/jesus.pdf [Consulta: junio 2016]

Lida, Miranda (2015). Historia del catolicismo en la Argentina entre el siglo XIX y el XX. Buenos Aires: Siglo XXI editores.

Louis, Annick (2014). "Las revistas literarias como objeto de estudio". En: HannoEhrlicher/ NanetteRißler-Pipka (eds.) Almacenes de un tiempo en fuga: Revistas culturales en la modernidad hispánica. Berlín: ShakerVerlag.

Mallimaci, Fortunato (1988). El catolicismo integral en la Argentina. Buenos Aires: Biblos.

Masiello, Francine (1986). Lenguaje e ideología. Las escuelas argentinas de vanguardia. Buenos Aires: Hachette.

Medrano, José María (2015). Los iniciales "Cursos de Cultura Católica" en Buenos Aires. Buenos Aires: Dunken.

Olazábal, Raúl Rivero de (1986). Por una cultura católica. El compromiso de una generación argentina. Buenos Aires, Editorial Claretiana.

Rancière, Jacques (2013). El espectador emancipado. Buenos Aires: Manantial.

Rancière, Jacques (2014). El reparto de lo sensible. Estética y política. Buenos Aires: Prometeo.

Rapalo, María Esther (2002). "Una empresa ideológica: Criterio". EN: GRAMUGLIO, María teresa (dir.) Historia Crítica de la literatura argentina. El imperio realista. Buenos Aires: Emecé.

Saítta, Sylvia. Regueros de tinta. El diario Crítica en la década de 1920. Buenos Aires, Sudamericana, 1998.

Sarlo, Beatriz (1992). "Intelectuales y revistas: razones de una práctica". Le discours culturel dans les revues latinoaméricaines (1940-1970). París : América-Cahiers du CRICCAL n 9/10, pp. 9-16).

Sarlo, Beatriz (1997). «Vanguardia y criollismo. La aventura de Martín Fierro ». En: Altamirano, Carlos y 
Sarlo,Beatriz. Ensayos argentinos, Buenos Aires: Ariel.

Wechsler, Diana (1999). "Impacto y matices de una modernidad en los márgenes: Las artes plásticas entre 1920 y 1945”. En: Burucúa, José Emilio (dir.) Nueva historia argentina: arte, sociedad y politica, Tomo I, Buenos Aires: Sudamericana, pp 269-314.

Zanatta, Loris (1996). Del Estado liberal a la Nación católica. Buenos Aires: Universidad de Quilmes.

\section{Notas}

1 Es interesante el desplazamiento que Gálvez establece según el criterio de inclusión: estéticos, religiosos y políticos, frente a un proyecto que intenta "democratizar" -o pluralizar- las intervenciones en relación con la creencia religiosa. De algún modo, esa clasificación impone, para el escritor argentino, la respuesta al fracaso del intento editorial.

2 Atilio Dell'Oro Maini renuncia en noviembre de 1929 cuando la comisión directiva decide que Criterio se oriente por los principios de la Acción Católica. Esto puede leerse en el número 90, 21 de noviembre de 1929, en el editorial “Criterio y la Acción Católica” firmada por “La Dirección”. En ese mismo número también aparece la renuncia de Dell’Oro Maini y de algunos de sus colaboradores. La lista incluye los nombres de Spotorno, Anzoátegui, Pico, Palacio, De Lara, Medioroz, Echeverrigaray, Jijena Sáchez, Prebisch, Aguirre, Delhez y Argerich.

3 Seguimos los planteos del filósofo francés Jacques Rancière (2013), quien en "Las paradojas del arte político" detecta en algunas prácticas artísticas un "modelo pedagógico de la eficacia de arte" (55) que supone que "el arte es político porque muestra los estigmas de la dominación, o bien porque pone en ridículo los íconos reinantes, o incluso porque sale de los lugares que le son propios para transformarse en práctica social, etc.” (54). Por su parte, la eficacia estética es propia del régimen estético del arte y establece una distacia y neutralización: "es la eficacia de la separación misma, de la discontinuidad entre las formas sensibles de la producción artística y las formas sensibles a través de las cuales ésta se ve apropiada por espectadores, lectores u oyentes" (58).

4 Sobre el tema ver Sarlo (1997 y 2003), Masiello (1986), Gilman (2006), Manzoni (2009).

5 En diálogo con Valéry, en 1926, el abate Bremond escribe este ensayo donde se nutre de la tradición poética inglesa para defender la idea de una poesía pura que recordase la interioridad y causara el mismo estado que la contemplación mística.

6 Es interesante, en este sentido, remarcar que si bien la publicación contaba con el apoyo del Arzobispado y el entusiasmo del sacerdote español Zacari\#as de Vizcarra, censor de los Cursos y capellán de importantes accionistas de la Editorial Surgo, los problemas no tardaron en aparecer ni bien empezó a circular la revista por varias cuestiones, tanto doctrinales o ideológicas como estéticas. En su relevo del archivo de Dell'Oro Maini, Devoto (2005) menciona que la belicosidad de algunos miembros del grupo, como Ernesto Palacio o César Pico, trajo fuertes enfrentamientos con el Directorio que "no estaba dispuesto a permitir la existencia de una publicación independiente y abierta al mundo laico y a las vanguardias como Criterio" (202); tampoco gustaban ciertas audacias que detentaban los jóvenes: como señala José Maria Medrano (2015), el Sansón desnudo de Juan Antonio, en una xilografía que ilustraba la portada del número 8 - 26 de abril de 1928fue criticado por Vizcarra, quien no lo encontró suficientemente cubierto, "mostrando las alcantarillas" (59).

7 La segunda muestra en los Cursos de Cultura Católica ya se había llevado a cabo y tuvo como exposición los trabajos realizados en esa escuela de arte sacro italiana. 